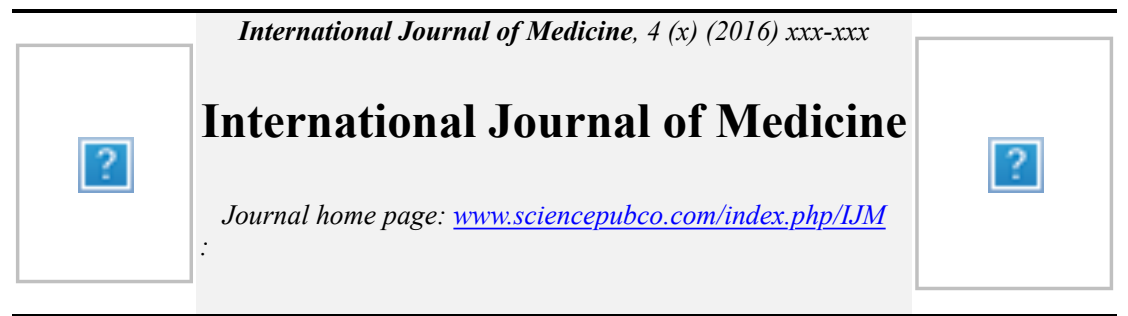

\title{
Neurofibrosarcoma: Case series in south-south Nigeria
}

\author{
Maurice E Asuquo $^{1}$, Victor I C Nwagbara ${ }^{1}$, Martin Nnoli ${ }^{2}$, John Ashindoitiang ${ }^{1}$, Theophilus Ugbem ${ }^{2}$, Samuel \\ Akpan ${ }^{1}$ \\ ${ }^{1}$ Department of Surgery, University of Calabar, Calabar, Nigeria \\ ${ }^{2}$ Department of Pathology, University of Calabar, Calabar, Nigeria [2] \\ *Corresponding authorE-mail:mauefas@yahoo.com,mauefas@unical.edu.ng
}

\section{Abstract}

Neurofibrosarcoma is a malignancy that occurs more frequently in patients with neurofibromatosis- 1 (NF-1) and rarely may arise independently. This is a presentation of 3 consecutive patients with histologic diagnosis of neurofibrosarcoma who presented to the University of Calabar Teaching Hospital, Calabar from 2011-2013. Two patients presented were associated with NF-1 and were a decade younger than the one without NF-1. Late presentation and poor follow up were notable underlying factors. Long term follow up of patients with NF -1 for early diagnosis and adequate treatment will improve outcome.

Keywords: Neurofibrosarcoma, neurofibromatosis -1. 


\section{Introduction}

Neurofibrosarcoma (NFS) is an uncommon malignancy occurring more frequently in patients with neurofibromatosis-1 (NF-1) (Asuquo 2005, Riccardi \&Powell 1989). This rare neoplasm may arise independently from somatic soft tissues and peripheral nerves in association with NF-1 or rarely as solitary sporadic finding accounting for 5\% of soft tissue sarcoma (STS) (Sar \& Eriap 2002, Liu et al 2013, Storm et al 1980, Nwagbara et al 2013). Plexiform neurofibroma may present at birth and may become malignant with time. Malignant transformation is the most dreaded complication of NF-1 which is estimated to affect about $5 \%$ of patients with NF1 (Asuquo 2005, Neville et al 1991). The following features may be pointers to possible malignant transformation: increase in size, hyper pigmentation, ulceration, bleeding and pain (Etiuma et al 2007). Surgery is the mainstay of treatment with complete surgical resection of tumour with margins of normal appearing surrounding tissue (Dabski et al 1990). Irrespective of initial or later control of local disease, some patients may develop metastatic disease (Odebode et al 2005). We present this study to highlight the challenges of management of NFS in a resource constrained setting.

\section{Case Series}

\subsection{Case report 1}

A 27 year old male presented to the surgical outpatient department (SOPD) as a referral from the orthopaedic department with history of recurrent right elbow swelling of over 22 years and pain of 3 months duration. This mass increased progressively in size but recently experienced pain that radiated to the right hand. Prior to this he had noticed other swellings located on the right side of the head and neck and below the right ear. Patient denied history of similar swellings in the siblings and other relatives. Had presented earlier to another hospital facility 6 months ago where there was an attempt to excise the elbow mass and was not informed of the nature of the mass.

Examination revealed a patient in relative good health, afebrile, anicteric, not pale and no peripheral lymphadenopathy. Vital signs were normal. He had multiple cutaneous nodules located on the head and neck region. The lesion behind the right ear measured $2 \times 3 \mathrm{~cm}$, soft, non tender. The lesion that prompted presentation was located on the anteromedial aspect of the right elbow extending into the forearm measuring $9 \times 5 \mathrm{~cm}$, firm, tender, and pigmented. There was no axillary lymphadenopathy. He also had multiple hyper pigmented skin patches that ranged in size from 1.5 $-2.5 \mathrm{~cm}$ mainly located on the trunk.

Haemogram revealed a packed cell volume (PCV) of $41 \%$, white cell count (WBC) of $5.8 \times 10^{9 / 1}$ (lymphocytes $53 \%$, neutrophils $45 \%$, eosinophils $2 \%$ ). Electrolyte sedimentation rate (ESR) $13 \mathrm{mmHg}$, human immunosuppression virus (HIV) was non reactive and urinalysis was normal. X-Ray of the right elbow and chest X-ray were normal. Histology revealed tumour composed of bundles of malignant spindle shaped cells with wavy slender nuclei and eosinophilic cytoplasm. Cells are arranged in storiform and herring bone pattern with abnormal mitotic figures in some areas - 


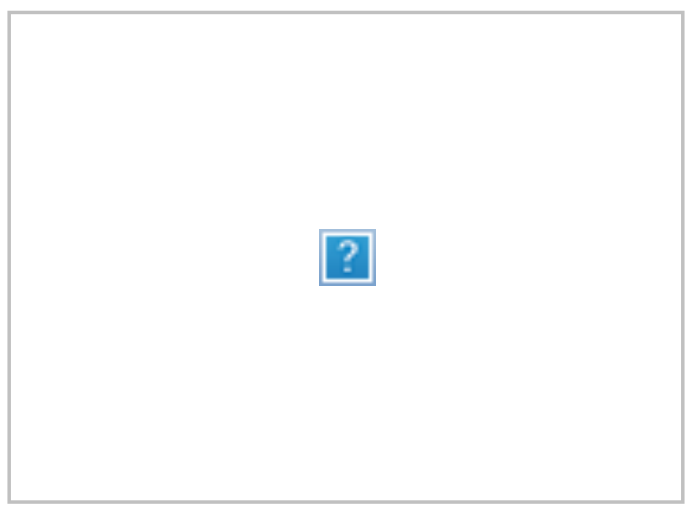

Figure 1a, Top - Photomicrograph

H\&E x 40 - Neurofibrosarcoma

Figure 1b, Bottom - Photomicrograph

H\&E x 100 - Neurofibrosarcoma

A diagnosis of NFS complicating plexiform neurofibroma (PNF) in a patient with NF-1 was made. He was counseled for surgery but however left against medical advice.

\subsection{Case report 2}

A 25 year old male presented with a painful mass located on the left side of the back noticed 23 years ago, 2 years after birth. This mass was noticed to increase in size and associated with pain in the last 4 months. An attempt was made at incising the mass at a tradomedical facility to no avail. Following this, he could no longer lay on the back hence the presentation in our facility. He is the $3^{\text {rd }}$ child in a family of 4 children. He also noticed other swellings in the other parts of the body with some hyper pigmented spots. Similar symptoms have not been noticed in any other siblings or close relatives. On examination, he was in satisfactory general health condition with normal vital signs. Afebrile, anicteric, not pale, no pedal oedema or peripheral lymphadenopathy. There were multiple nodular lesions and multiple café au lait spots with irregular edges and diameter that ranged from $1.5-2.5 \mathrm{~cm}$ found mainly in the trunk. The largest lesion was located obliquely on the left side of the back, oval in shape, measuring $7 \times 3.5 \mathrm{~cm}$, firm, tender, hyper pigmented,

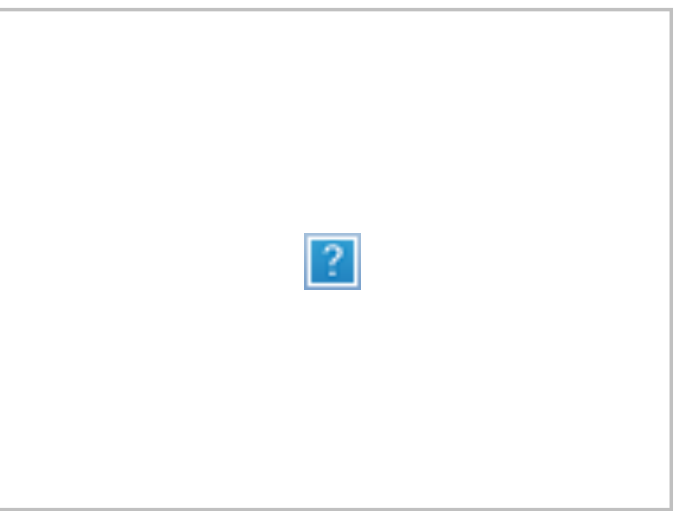

Figure 2 - Clinical photograph -

Neurofibrosarcoma

Chest and abdominal examination was unremarkable.

Haemogram showed a PCV of $36 \%$, WBC $5.3 \times 10^{9} / 1$ (neutrophils $51 \%$, eosinophils $2 \%$, lymphocytes $47 \%$ ). Urinalysis was normal and histology revealed neurofibrosarcoma. A diagnosis of NFS in a patient with NF-1 was made.

He was offered excision biopsy with an uneventful post operative outcome. Four months post surgery he was lost to follow up. 


\subsection{Case report 3}

A 38 year old male presented with left sided facial swelling of 4 years duration. This swelling increased in size progressively as a painless mass until 2 months ago when mass grew rapidly and pain set in thereby prompting presentation. There was no pain on mastication nor difficulty in swallowing. Patient is the first child in the family with no history of similar swelling in other siblings. He works with a construction company.

Examination revealed a hemispherical mass that measured $10 \mathrm{x} 8 \mathrm{~cm}$ overlying the left parotid area,

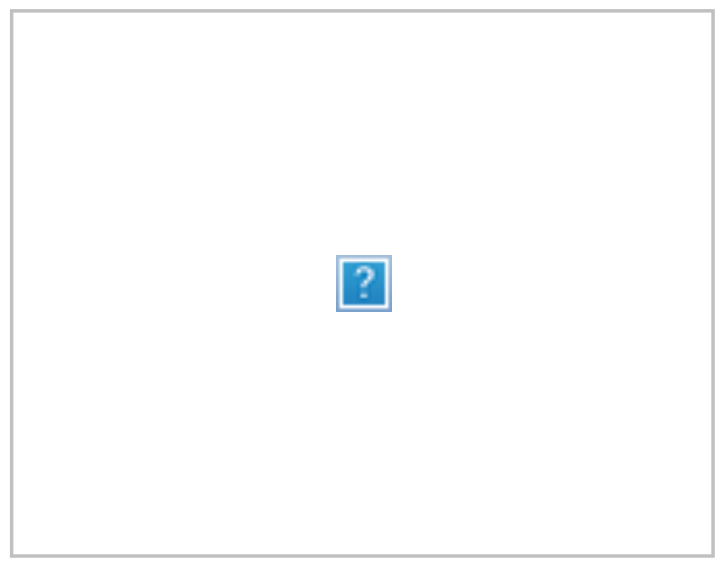

Figure 3 Clinical photograph - Neurofibrosarcoma.

It was mildly tender, smooth surface with areas of soft and firm consistency. Movement was not restricted on clenching of the teeth and there was no facial nerve deficit and no regional lymphadenopathy. Chest and abdominal examination was unremarkable.

Haemogram revealed PCV of $37 \%$, WBC $5.1 \times 10^{9} / 1$ (neutrophils $52 \%$, eosinophils $2 \%$, lymphocytes $46 \%$ ), ESR $110 \mathrm{mmHg}$. HIV serology was negative and urinalysis was normal. X-Ray of the head and chest were unremarkable. Ultrasound scan (USS) reported a well circumscribed mass with no calcification and suggested a diagnosis of left parotid adenoma and recommended biopsy. A clinical diagnosis of pleomorphic adenoma of the parotid gland was made. Histology was reported as NFS. He was offered an excision and post operative period was unremarkable. However, patient was lost to follow up 3 months post surgery.

\section{Discussion}

Neurofibrosarcoma arising from malignant transformation of neurofibroma or de novo appearance presents a threat to patients (Nwagbara et al 2013, Etiuma et al 2007). It may arise in the skin (cutaneous NF) associated with NF-1 or in peripheral nerve (solitary NF) with or without features of NF-1 as depicted by the patients presented (Etiuma et al 2007). This malignancy accounts for 5-7\% of soft tissue sarcoma (STS). It is in keeping with a report of NFS that accounted for $6.4 \%$ of STS in the authors setting (Banerjee et al 2013, Asuquo et al 2016). However, in another study, Riccardi and Powell reported that $3.5 \%$ of patients with NF-1 develop NFS or one of its variants (Riccardi \& Powell 1989).

Neurofibromatosis has been classified into 8 types with NF-1 as the commonest form accounting for about $90 \%$ of cases (Etiuma et al 2007). This inherited genetic disease arise from alteration of NF-1 gene and is a known risk factor for NFS as typified two patients presented in this report. The risk of malignancy in NF is estimated at about 3\% with the risk higher in long standing PNF attached to nerve trunks in the neck and extremeties (Etiuma et al 2007). It is estimated that patients with NF-1 have $315 \%$ additional 
risk of malignant disease during their lifetime (Nyandaiti et al 2009).

The ages of the patients with NF-1 who develop NFS are twice likely to be under the $3^{\text {rd }}$ decade (Riccardi \& Powell 1989). This is in keeping with 2 cases aged 25 and 27 years. The tumour is rare in children, none of the cases presented were paediatric (Neville et al 2003). The patient with solitary lesion, not associated with NF-1 was a decade older than those with NF-1, thereby highlighting the possible significance of NF-1 as an independent risk factor for NFS. The male to female ratio has been reported as 2: 1, we report an all male case series (Banerjee et al 2013). However, a female patient with NFS of the foot was earlier reported in this centre (Asuquo 2005). Report from Banerjee R et al indicated the limbs as the commonest affected site (Banerjee et al 2013). Liu X et al reported the first case of NFS of the gallbladder, in addition indicated the trunk, retroperitoneum and the head and neck as usual locations for NFS in order of decreasing frequency (Mankin \& Homicek 2005).

It is commonplace for patients with NF to remain in good health with the symptom of skin lump until onset of sudden increase in the size of the skin mass, pain and soreness occur, thereby heralding the onset of the most dreaded complication of NFS (Odebode et al 2005, Banerjee et al 2013). In the authors setting, late presentation of patients with malignancy in advanced stage is not uncommon as was our experience in this report. Patients have been reported to present with metastatic disease with predilection for the lungs (Asuquo 2005). In addition to malignant transformation, metastasis and cystic degeneration may rarely occur (Nwagbara et al 2013, Etiuma et al 2007).

The hallmark of diagnosis is histology with characteristic malignant bundle of spindle shaped cells with slender wavy nuclei and eosinophilc cytoplasm. Cells are arranged in wholly storiform and herring bone pattern with hypo cellular areas with loose myxoid stroma, Figures 1a\&b (Dabski et al 1990).

The mainstay of treatment is surgery with tumour free margins aimed at local control and prevention of recurrence (Odebode et al 2005). However, in stages II and III NFS with or without NF-1 is a very malignant lesion. Radical wide en bloc dissection of the primary lesion in addition to preoperative radiation and chemotherapy with Adriamycin may minimise local recurrence (Odebode et al 2005). Metachronous spinal and lung metastases have been reported. Local control can be achieved in about $80 \%$ of patients with NFS by wide local excision, adjuvant chemo radiation is recommended as most patients die of systemic metastasis (Sar \& Eraip 2002).

\section{Conclusion}

Long term follow up of patients with NF is highly recommended in view of possible development of malignancy. Early presentation, diagnosis and treatment are recommended. Provision of facility for chemotherapy and radiation will improve outcome.

\section{References}

1. Asuquo ME (2005) Neurofibromatosis - Complicating Neurofibromatosis - 1: Case Report and Review of Relevant Literature. Nig Postgrad Med J 12(3): 233-236

2. Riccardi VM, Powell PP (1989) Neurofibrosarcoma as a complication of von Recklinghausen neurofibromatosis. Neurofibromatosis 2(3): 152-165

3. Sar C, Eraip L (2002) Metastatic spinal neurofibrosarcoma. Arch Orthop Trauma Surg 122(2): 106-108

4. Liu X, Tang K, Siu L, Xu G (2013) Neurofibroma of the gallbladder: a case report. World Journal of Surgical Oncology 11: 189 (pp 1-4)

5. Storm FK, Eilber FR, Mirra J, Morton DL (1980) Neurofibrosarcoma. Cancer 45: 126129

6. Nwagbara V, Asuquo M, Akpan S, Eduwem D, Omotoso A, Ugbem T (2013) Giant solitary intermuscular cystic plexiform neurofibroma of the thigh: A case report and literature review. Int J Case Report Med Doi: 10.5171/2013.436550 
7. Neville BW, Hann J, Narang R, Garen P (1991) Oral neurofibrosarcoma associated with neurofibromatosis type-1. Oral Surg Oral Med Oral Pathol 72(4): 456-461

8. Etiuma AU, Bassey OO, Asuquo ME, Ebughe G (2007) Multiple Neurofibrosarcoma In a Patient with Neurofibromatosis -1. A case report. Nig J Surg 13(1-2): 29-31

9. Dabski C, Reiman HM, Muller SA (1990) Neurofibrosarcoma of the skin and subcutaneous tissues. Mayo Clin Proc 65(2): 164-172

10. Odebode TO, Afolanyan EAO, Adigun IA, Daramola OOM (2005) Clinicopathological study of neurofibromatosis type-1: an experience in Nigeria. Int J Dermatol 44: 116-120

11. Banerjee R, Bandopadhyay D, Abilash VG (2013) Epidemiology, pathology, types and diagnosis of soft tissue sarcoma: A Research Review. Asian J Pharm Clin Res 6(suppl 3): $18-25$.

12. Asuquo ME, Nnoli M, Nwagbara VIC, Ashindoitiang J, Ugbem T, Akpan S (2016) Liposarcoma: experience in a tropical setting. Int J Med 4(1): 6-9.

13. Nyandaiti YW, Tahir C, Nggada HA, Ndahi AA (2009) Clinicopathologic presentation and management of neurofibromatosis among north-eastern Nigerians: A six year review. Nig Med J 50(4): 80-83.

14. Neville H, Corpron C, Blakely ML, Andrassy R (2003) Paediatric Neurofibrosarcoma. J Pediatr Surg 38(3): 343-346.

15. Mankin HJ, Homicek FJ (2005) Diagnosis, classification and management of soft tissue sarcomas. Cancer Control 12: 5-21.

Copyright $\odot 2014$ Authors. This is an open access article distributed under the Creative Commons Attribution License, which permits unrestricted use, distribution, and reproduction in any medium, provided the original work is properly cited. 